\title{
A new, phenotypically distinct subpopulation of Regulatory Killer T ex-Th17 cells expressing CD4 ${ }^{\text {low }}$ CD25 ${ }^{\text {hi }}$ CD49 ${ }^{\text {hi }}$ Foxp3 $^{\text {hi }}$ ROR $^{\text {low } I L-17^{\text {low }}}$
}

\author{
Maria S. Sayapina
}

\section{Corresponding author: Maria S. Sayapina maria.sayapina@mail.ru}

\section{Laboratory of Experimental Immunology, Immunology Frontier Research Center, Osaka University, Osaka 565-0871, Japan}

Author Approval The author has seen and approved the manuscript

Th17 and regulatory T (Treg) cells are integral in maintaining immune homeostasis and Th17Treg imbalance is associated with inflammatory immunosuppression in cancer. Here it is shown that in addition to ROR+Foxp3+ cells eTreg cells are a source of ex-Th17 CD $4{ }^{\text {low }} \mathrm{CD} 25^{\text {hi }} \mathrm{CD} 49^{\text {hi }}$ Foxp $3{ }^{\text {hi }}$ (Regulatory Killer T - RKT) cells while the latest are much more suppressive. Moreover, we have identified a set of key cytokines that favor the generation and expansion ex-Th17 Foxp $3^{\text {low }}$ cells. These findings should accelerate efforts to define the function of this new subset of Treg cells in the immune response to cancer.

Key words: Regulatory Killer T ex-Th17 cells, eTregs, CD $4{ }^{\text {low }}$ CD $25{ }^{\text {hi }}$ CD $499^{\text {hi }}$ Foxp $3{ }^{\text {hi }}{ }^{\text {ORR }}{ }^{\text {low }}$ IL$17^{\text {low }}$ cells.

\section{Introduction}

Treg cells consist of functionally diverse subsets of immune suppressive $\mathrm{T}$ cells that play a crucial role in the modulation of immune responses and the reduction of deleterious immune activation $[1,2]$. Treg cells may participate in the progression of cancer, especially with regard to the ability of Treg cells to promote the development of tumors [3]. It was described that the levels of intratumoral Treg cells correlating with better or worse outcomes depending on the tumor type $[4,5]$. Recent studies indicate that human ovarian cancer cell line SKOV-3 could convert, in the presence of IL-2, Treg into Th17 cells. These results support the ability of the tumor microenvironment to regulate and expand IL-17-producing T-helper (Th17) cells. Similar results were obtained upon stimulation of CD4+ $\mathrm{T}$ cells in the absence of tumors but in the presence of IL-1 $\beta / \mathrm{IL}-6$ and IL-2 [6]. Cytokine profile analysis revealed that ovarian tumor cells, tumor-derived fibroblasts, and antigenpresenting cells (APCs) secrete IL-1 $\beta /$ IL-6 [7]. IL-1 $\beta$ is a potent inducer of Th17 cell differentiation and expansion, whereas IL-6 is capable of expanding memory Th17 cells [8]. Gene profile analysis revealed that SMAD 6 and HDAC 11 are 
hyperexpressed in ovarian cancer cell line SKOV-3 [9]. In its turn Smad6 is transcriptionally induced by the antiinflammatory cytokine TGF- $\beta$. On the one hand, the importance of the concentration of TGF-b was illustrated in selectively regulating Treg and Th17development. Low concentrations of TGF-B favor Th17 differentiation by enhancing IL- 23 receptor (IL- 23 R) expression, while high concentrations promote Treg differentiation by inhibit IL-23 R upregulation [10]. On the other hand, it was also described that ovarian tumor cells secreted a high amount of latent TGF- $\beta$ (inactive form), but the level of active form of TGF- $\beta$ was very low ( $\leq 30$ $\mathrm{pg} / \mathrm{ml}$ ) or undetectable because of its short half-life $[8,11]$. Importantly, most of all types of tumors secrete high amount of TGF- $\beta$. Whereas overexpression of HDAC11 was associated with inhibition of expression of the gene encoding IL-10 and higher IL-12 mRNA expression [12]. IL-12 and IL-23 shared the same IL-12R $\beta 1$ receptor subunit and are characterized by overlapping effects on target cells. As shown before, IL-23 stimulation is not only crucial for attaining full effector function but also necessary for double expression of IL-17A and IFN- $\gamma$, induction of T-bet and subsequent deviation toward IFN- $\gamma$ production[13]. Here, it was provided an insightful mechanism by which ex-Th17 $\mathrm{CD} 4{ }^{\text {low }} \mathrm{CD} 25^{\text {hi }} \mathrm{CD} 49^{\text {hi }}$ Foxp $33^{\text {hi }}$ cells are generated from eTreg cells and regulated by cytokines that favor the generation and expansion exTh17Foxp $3^{\text {low }}$ cells.

\section{Results}

I conducted 3 experiments aimed at deriving eTreg cells using BALB/c mice ( $1^{\text {st }}$ time $)$ and Foxp3-GFP-DTR (2 times), CD4+CD25+FOXP3 $3^{\text {DTR-GFP }}$ cells were isolated from lymph nodes and spleen by flow cytometry cell sorting to high purity and stimulated with anti-CD3/CD28 coated Dynobeads and IL-2 (Fig. 1). FACS analyses of the isolated population was at day 3 after stimulation. As shown in Figure 2, ex-Th17 CD $4{ }^{\text {low }} \mathrm{CD} 25^{\text {hi }} \mathrm{CD} 49^{\text {hi }}$ Foxp $3{ }^{\text {hi }}$ cells were clearly detectable in populations from the purified CD4+CD25+ T-cell fractions after in vitro expansion. Staining with anti-IL-17 antibody revealed that ex-Th17 CD $4{ }^{\text {low } C D} 25^{\text {hi }}$ CD $49{ }^{\text {hi }}$ Foxp $3{ }^{\text {hi }}$ cells secreted low level of IL-17, although ROR+FOXP3 $+\mathrm{T}$ cells produced high level of IL-17 Further experiments revealed that freshly isolated $\mathrm{CD} 4{ }^{\text {low }} \mathrm{CD} 25^{\text {hi }} \mathrm{T}$ cells were strongly positive for CD49b and Foxp3 molecules and weakly positive for ROR (Fig. 3). 

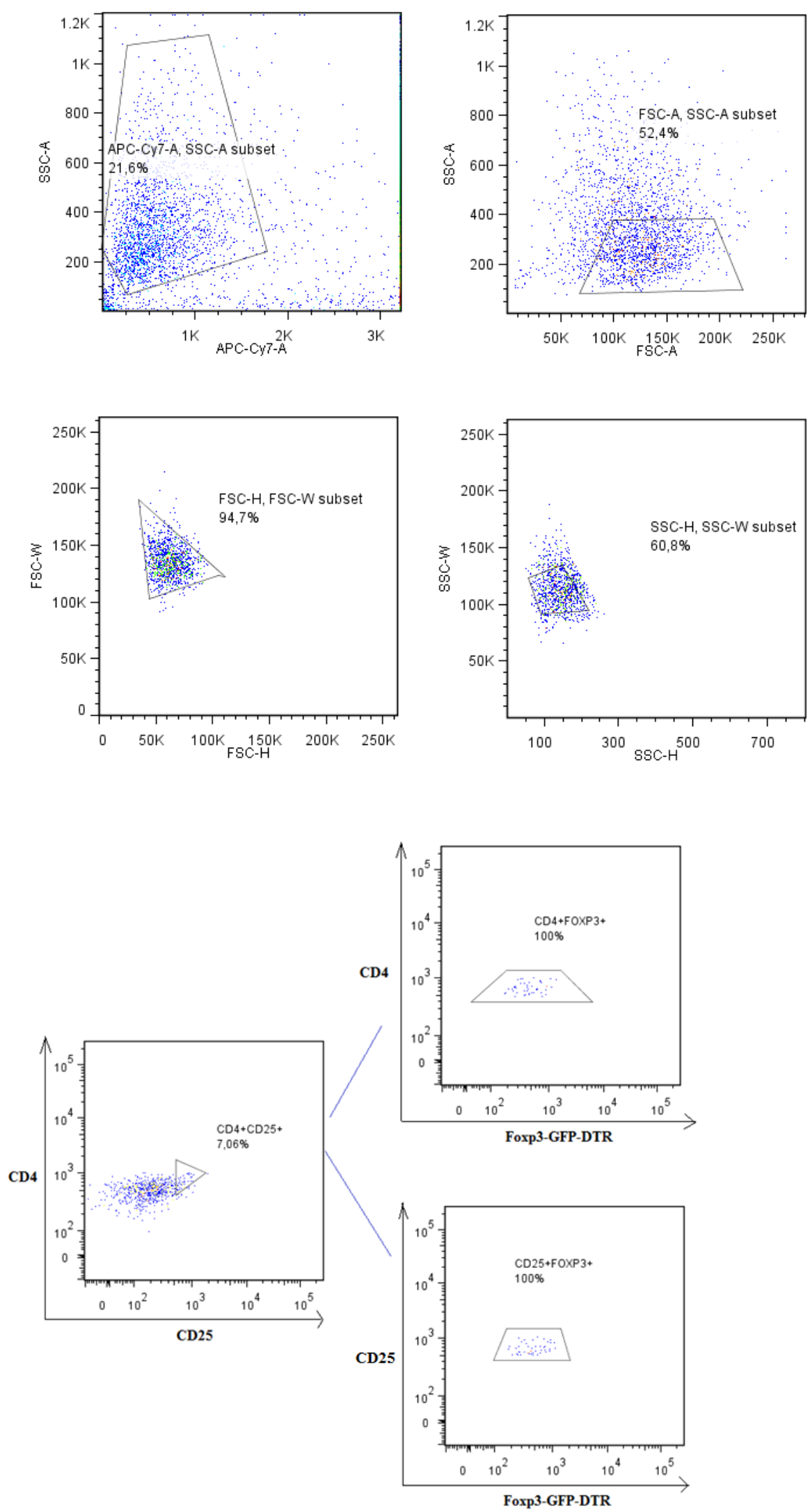

Figure 1. Sorting strategy and the purities of resultant population CD4+CD25+Foxp3+T cells. 

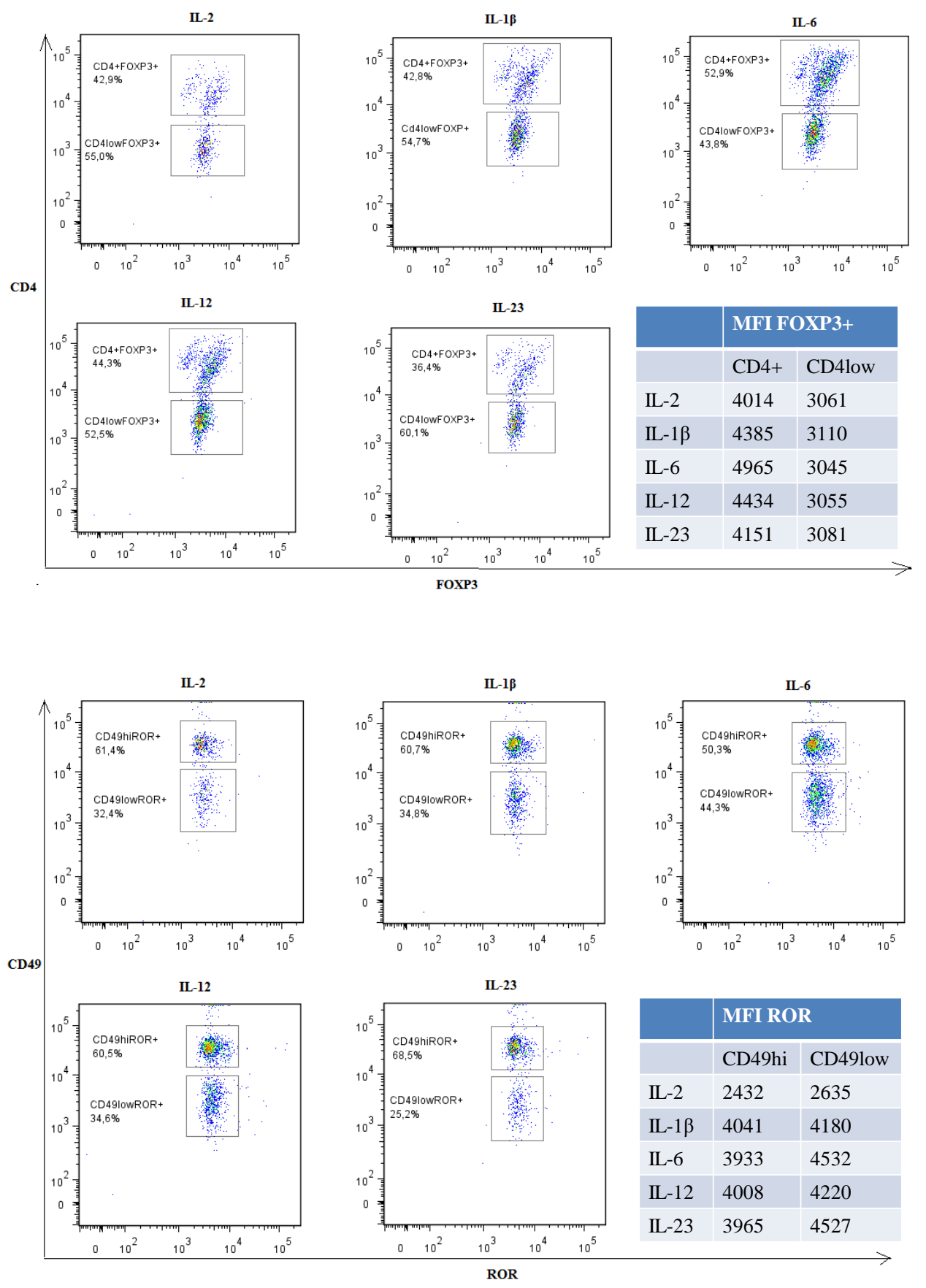

Figure 2. CD $4^{\text {low }} \mathrm{T}$ cells express Foxp3 and CD49b.

So I am the first who describe this subpopulation of ex-Th17 CD $4{ }^{\text {low }} C D 25^{\text {hi }} C D 499^{\text {hi }}$ Foxp $3{ }^{\text {hi }}$ cells. 

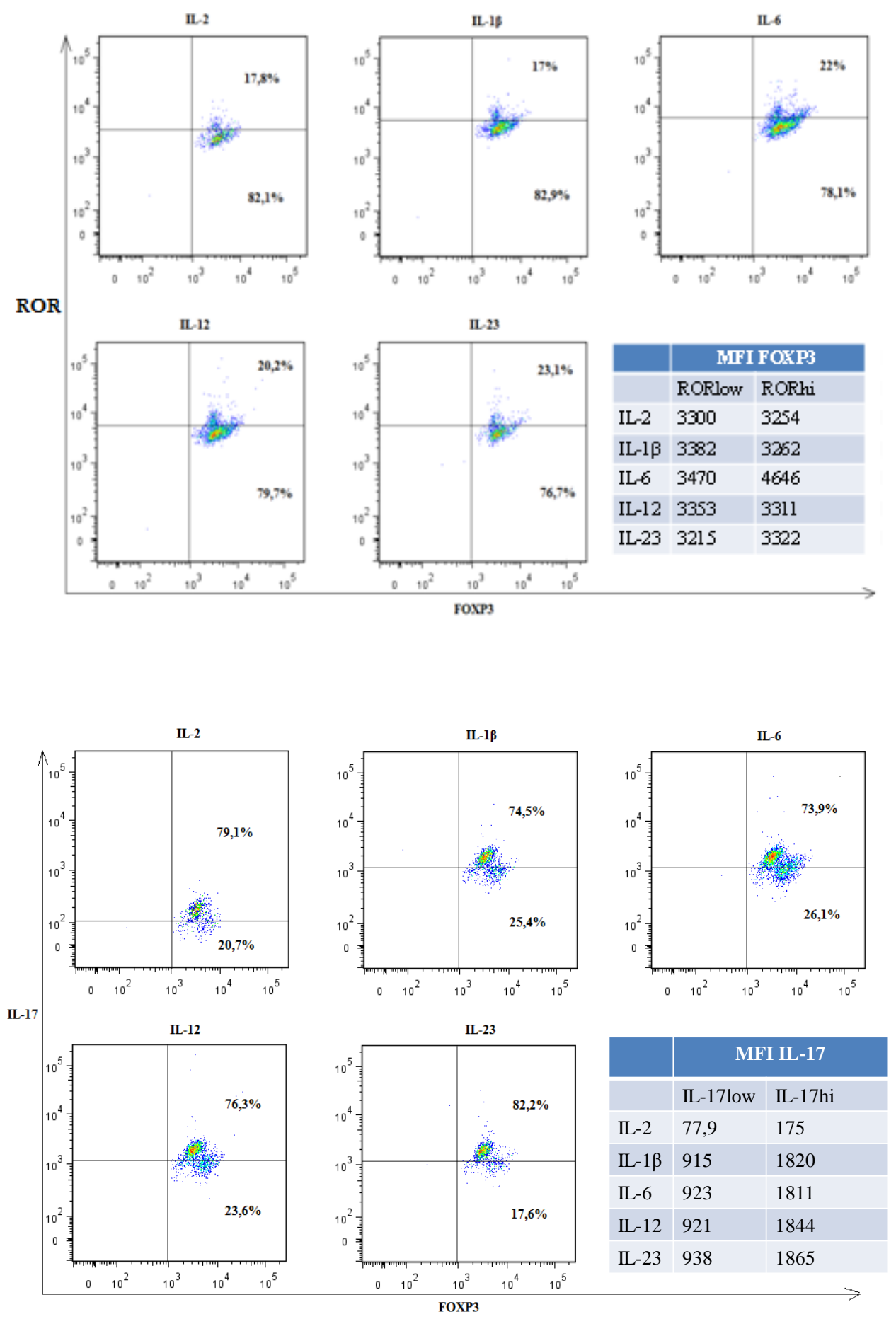

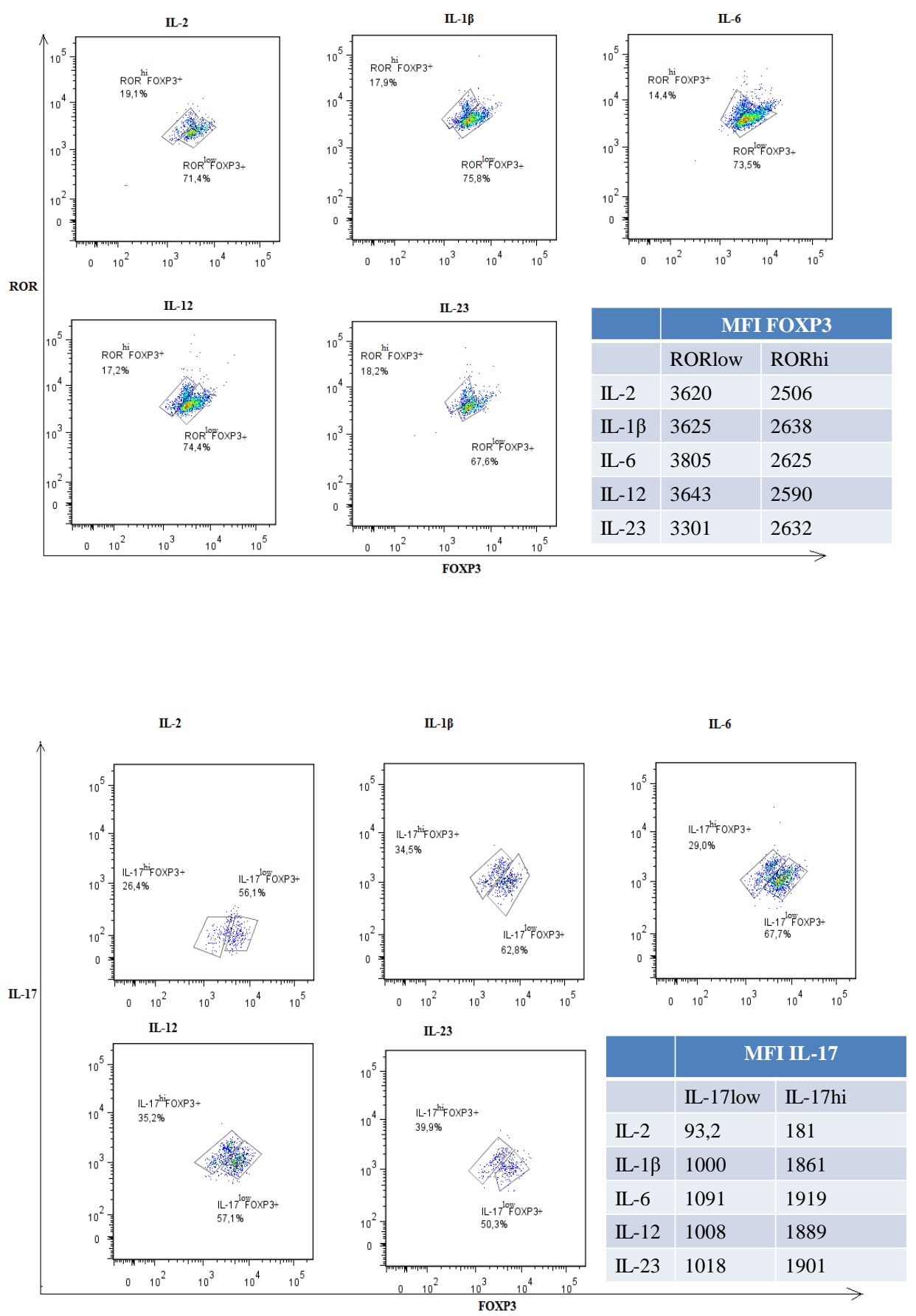

Figure 3. CD $4{ }^{\text {low }} \mathrm{CD} 25^{\text {hi }} \mathrm{CD} 49^{\text {hi }}$ Foxp $3{ }^{\text {hi }}$ cells express low level of IL-17 and ROR.

We also sought to determine the role of key cytokines, as discussed earlier, in the generation and expansion of exTh17Foxp $3^{\text {low }}$ cells.

In the next stage we tested the effects of IL-12, IL-1 $\beta$, IL-6, IL-23 on exTh17Foxp3 ${ }^{\text {low }}$ differentiation and expansion by using Treg cells from Foxp $3^{\text {DTR-GFP }}$ mouse. IL-2-containing medium provided a baseline for comparison. Analysis of ex-Th17 CD $4{ }^{\text {low } C D} 25^{\text {hi }} C D 49^{\text {hi }}$ Foxp $3{ }^{\text {hi }}$ 
cells revealed that IL-23 plays a more prominent role in differentiation and expansion of exTh-17 Foxp3 $3^{\text {low }}$ cells than do IL-12 and IL-1 $\beta$. By contrast, IL-6 stimulated IL-17-producing ROR+Foxp3+T suppressive cells.

\section{Discussion}

In this work, we have described the new subpopulation of ex-Th17 CD $4{ }^{\text {low }} \mathrm{CD} 25^{\text {hi }} \mathrm{CD} 49^{\text {hi }}$ Foxp $3{ }^{\text {hi }}$ cells. Importantly, our data demonstrate the differentiation of eTreg cells to ROR+Foxp3+ cells and exTh17 RKT cells. Bryl et al. have previously reported population of peripheral blood T cells with reduced CD4 and high $\mathrm{CD} 25$ expression $\left(\mathrm{CD} 4{ }^{\text {low }} \mathrm{CD} 25^{\text {high }}\right)$, that are able to nonspecifically suppress the proliferation of autologous, previously polyclonally activated CD4+lymphocytes and to kill them by direct contact. $\mathrm{CD} 4{ }^{\text {low }} \mathrm{CD} 25^{\text {high }} \mathrm{T}$ cells expressed significant amounts of both intracellular perforin and granzyme B. At the same time common NK/NKT antigens, including: CD16, CD56, CD94, CD158b, CD161 and invariant NKT (iNKT), - were not present on CD4 ${ }^{\text {low }} \mathrm{T}$ cells [14].

Also using whole-genome microarray data sets of the Immunological Genome Project, it was demonstrated a closer transcriptional relationship between NK cells and T cells than between any other leukocytes, distinguished by their shared expression of genes encoding molecules with similar signaling functions, including NT cells and Treg [15]. In terms of common expression of Zap70 and Prscq and potential expression of perforin and granzyme B we concluded that the definition of a CD $4{ }^{\text {low }} \mathrm{CD} 25{ }^{\text {hi }} \mathrm{CD} 499^{\text {hi }}$ Foxp $3{ }^{\text {hi }}$ cells phenotype is enough to unambiguously detect and study the regulatory function of new subpopulation called Regulatory Killer T - RKT cells which fulfils the current phenotypic criteria identifying the exTh17 RKT cells by simultaneously expressing low amounts of ROR and IL-17A.

Thus, the relative concentration of IL-2, IL-12, IL-1 $\beta$ and IL-23 in the tumor microenvironment may be a critical factor for the generation of exTh17 RKT that will be converted into INF- $\gamma$ producing exTh17Foxp $3^{\text {low }}$ (exTh17/Th1) cells. Based on these findings, it was predicted that cytokine milieu (low amounts of TGF- $\beta$ and high amounts of IL-2, IL-12, IL-1 $\beta$ and IL-23) in cancer favors the generation and expansion of exTh17Foxp $3^{\text {low }}$ cells, although further studies are needed to validate this concept.

In terms of several types of tumors secrete some cytokines, for example colorectal cancer express high level of IL-23, ovarian cancer - IL-12 (I am planning to prove it) the combination of IL-2, IL-12, IL-1 $\beta$ and IL-23 in different ways enhanced the differentiation of exTh17Foxp3 $3^{\text {low }}$ (exTh17/Th1) cells from eTreg cells while retaining their ability to expand ROR+Foxp3+ T cells. IL-23 as a critical factor driving exTh17Foxp $3^{\text {low }}$ cell expansion. Our 
findings clearly support the emerging concept that tumor environmental factors drive the generation and expansion of exTh17Foxp $3^{\text {low }}$ cells. This knowledge should accelerate efforts to describe the new subpopulation ex-Th17 CD4 ${ }^{\text {low }} \mathrm{CD} 25^{\text {hi }} \mathrm{CD} 49^{\text {hi }}$ Foxp3 ${ }^{\text {hi }}$ (RKT) cells in more detail and create several drugs for several immunogenic types of tumors (melanoma, ovarian cancer, renal cancer, colorectal cancer) on the basis of IL-2, IL-12, IL-1 $\beta$ and IL-23 that will be delivered locoregionally (intraperitioneally, intrahepatic artery etc) to decrease systemic toxicity.

\section{Methods}

\section{Cell culture}

CD4+Tcells that were isolated from FDG mouse by negative selection with mouse CD4+Isolation Kit and were further separated into CD4+CD25+FOXP3 ${ }^{\text {DTR-GFP }}+$ Tregcells using a FACS ARIA II instrument. Sorted $1,2 \times 10^{\wedge} 5$ eTreg cells were cultured in the presence of antiCD3- and anti-CD28-coated (2,5 mcl) Dynabeads and IL-2 (100U/ml). In some cultures IL-12 (30ng/l), IL-1 $\beta$ (30ng/ml), IL-6 (30ng/ml), IL-23 (30 ng/ml) were added. Cells were analysed with an FACS Canto instrument 3 days later.

Cells were cultured in culture medium (RPMI-1640 supplemented with $100 \mathrm{U} / \mathrm{mL}$ penicillin, 100 $\mathrm{g} / \mathrm{mL}$ streptomycin, $5 \mathrm{mM}$ 2-mercaptoethanol, $0.05 \%$ and $10 \%$ fetal bovie serum $[\mathrm{FBS}]$ ) at $37^{\circ} \mathrm{C}$, and 5\% $\mathrm{CO} 2$, in 96-well round-bottom plates (Greiner, Frickenhausen, Germany).

\section{Antibodies and reagents}

Allophycacocyanin (APC)- and Cy7- conjugated anti-CD4 (RM 4-5) mAb, phycoerythrin (PE) and Cy7-conjugated ant-CD4(RM 4-5) $\mathrm{mAb}$, peridinin chlorophyll protein complex (PerCP)andCy5.5-conjugated anti-CD25 (PC-61) mAb, phycoerythrin (PE) anti-ROR (Q31-378) mAb were purchased from Bioscience. Brilliant Violet 421(BV421) - conjugated anti-IL-17 (TC-1118H 10.1) mAb, Alexa Fluor 647-conjugated anti-CD49b (DX5), LIVE/DEAD Fixable Near-IR Dead Cell Stain Kit were purchased from Biolegend. Recombinant murine IL-6, IL-12, IL-23, IL-1 $\beta$ were purchased from Sarstedt and Bioscience.

All results were received by the author personally in 01.2018 and reported on a scientific club in the laboratory on January 29, 2013, and this was the continuation of the author's dissertation work [16].

ACKNOWLEDGMENTS. I thank Professor Shimon Sakaguchi for his encouragement and support. 


\section{References}

1.Zhang et al. Analysis of CD81 Treg cells in patients with ovarian cancer: a possible mechanism for immune impairment Cellular \& Molecular Immunology 2015 12, 580-591

2.Facciabene A, Motz GT, Coukos G. T-regulatory cells: key players in tumor immune escape and angiogenesis. Cancer Res 2012; 72: 2162-2171.

3. Viehl CT, Moore TT, Liyanage UK, Frey DM, Ehlers JP, Eberlein TJ et al. Depletion of CD41CD251 regulatory $\mathrm{T}$ cells promotes a tumorspecific immune response in pancreas cancerbearing mice. Ann Surg Oncol 2006; 13: 1252-1258.

4. Liu S, Foulkes WD, Leung S, Gao D, Lau S, Kos Z et al. Prognostic significance of FOXP31 tumor infiltrating lymphocytes in breast cancer depends on estrogen receptor and human epidermal growth factor receptor-2 expression status and concurrent cytotoxic T-cell infiltration. Breast Cancer Res 2014; 16: 432.

5. Salama P, Phillips M, Grieu F, Morris M, Zeps N, Joseph D et al. Tumor-infiltrating FOXP31 $\mathrm{T}$ regulatory cells show strong prognostic significance in colorectal cancer. J Clin Oncol 2009; 27: 186-192.

6. Leveque et al. Interleukin 2-mediated Conversion of Ovarian Cancer-associated CD4+ Regulatory $\mathrm{T}$ Cells Into Proinflammatory Interleukin 17-producing Helper $\mathrm{T}$ Cells. J Immunother 2009;32:101-108

7. Nilsson MB, Langley RR, Fidler IJ. Interleukin-6, secreted by human ovarian carcinoma cells, is a potent proangiogenic cytokine. Cancer Res. 2005;65:10794-10800.

8. Miyahara et al. Generation and regulation of human CD4+IL-17-producing T cells in ovarian cancer. PNAS; October 7, 2008; vol. 105, no. 40; 15505-15510

9.http://amp.pharm.mssm.edu/Harmonizome/gene_set/SKOV3/CCLE+Cell+Line+Gene+Expres sion+Profiles

10. Zhou et al. TGF-beta-induced Foxp3 inhibits $\mathrm{T}(\mathrm{H}) 17$ cell differentiation by antagonizing RORgammat function. Nature. 2008 May 8;453(7192):236-40.

11. Carr TM, Adair SJ, Fink MJ, Hogan KT (2008) Immunological profiling of a panel of human ovarian cancer cell lines. Cancer Immunol Immunother 57:31-42. 
12. Villagra et al. The histone deacetylase HDAC11 regulates the expression of interleukin 10 and immune tolerance. NATURE IMMUNOLOGY. VOLUME 10 NUMBER 1 JANUARY 2009; pp. 92-100

13. Hirota et al. Fate mapping of IL-17-producing T cells in inflammatory responses. nature immunology VOLUME 12 NUMBER 3 MARCH 2011 pp. 255-260

14. Bryl et al. Human CD4low CD25high regulatory T cells indiscriminately kill autologous activated T cells. Immunology 2009, 128, e287-e295

15. Bezman et al. Molecular definition of the identity and activation of natural killer cells. Nature Immunology VOLUME 13 NUMBER 10 OCTOBER 2012 1000-1009

16. http://www.ronc.ru/node/2246 
E. 2

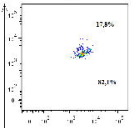

Eogk.

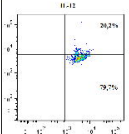

$|1-|||$

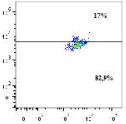

II -21

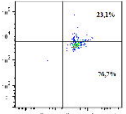

$=10^{*} \quad 10^{2} \quad 10^{4} \quad 1 t^{n}$
II 6

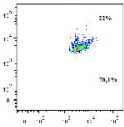


II 2

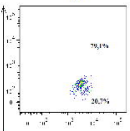

II 17

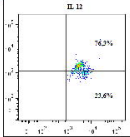

IL $\mathrm{tP}$

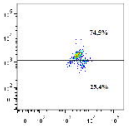

II 35

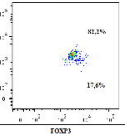

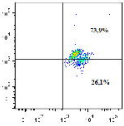


II. 2

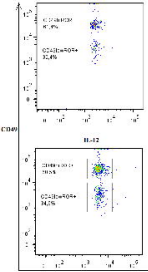

II

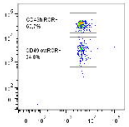

11.-23

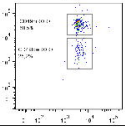

WN 

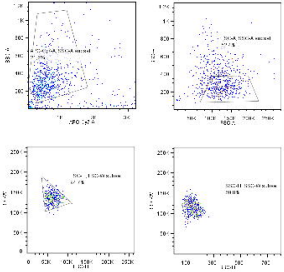

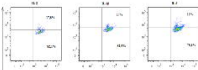

cora.

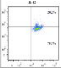

t.

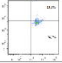

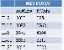



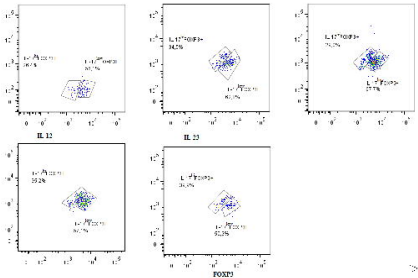
II - 2

I I 18

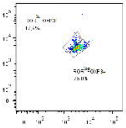

II. II

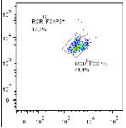

20 2 0 - 1

मा

ts

n:aरr:as *1

$r 15$

Kerk
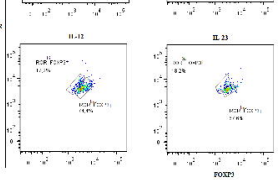

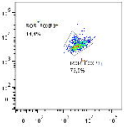



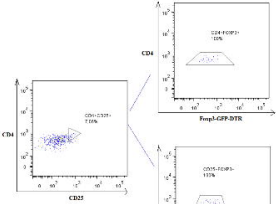

C)125

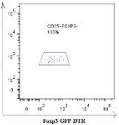

